\title{
Estimation of Congestion Cost in the City of Kolkata-A Case Study
}

\author{
Aparajita Chakrabartty, Sudakshina Gupta \\ Centre for Urban Economic Studies, Department of Economics, University of Calcutta, Kolkata, India \\ Email: api09@rediffmail.com, sudakshinagupta@yahoo.co.in
}

Received 26 March 2015; accepted 25 May 2015; published 29 May 2015

Copyright (C) 2015 by authors and Scientific Research Publishing Inc.

This work is licensed under the Creative Commons Attribution International License (CC BY). http://creativecommons.org/licenses/by/4.0/

(c) (i) Open Access

\begin{abstract}
The demand for mobility has risen significantly all over the world as a result of the fast pace of urbanization. The situation is no different in India. In India, personal vehicles have increased tremendously to take care of this rising need for mobility as provision of public transport has been inadequate. This exponential growth of vehicles has led to traffic congestion which is a hindrance to mobility. Traffic congestion leads to increase in operating cost of vehicles, delay, pollution and stress. The problem is acute in the Indian city of Kolkata as the road space here is only $6 \% \mathrm{com}$ pared to $23 \%$ in Delhi and $17 \%$ in Mumbai. This paper makes an attempt to measure the external cost of congestion on the roads of Kolkata. The method used to measure the cost of congestion follows that of R. J. Smeed (1968). The result obtained or the cost of congestion estimated for the city of Kolkata indicates that there is a considerable monetary loss that is being incurred. An attempt to measure the cost of congestion in the city of Kolkata has not been made before, although studies have tried to estimate congestion in Kolkata city.
\end{abstract}

\section{Keywords}

Urbanization, Transportation, Motorization, Traffic Congestion, External Cost, Congestion Cost

\section{Introduction}

The role of transportation becomes very important in a situation of rapid urbanization, which is the increase over time in the population of cities in relation to the region's rural population. Since the end of the Second World War, there have been rapid urbanization and growth in economic activities in third world cities, resulting in high demand for mobility there. Urban transport in the third world countries is characterized by huge traffic growth along with shortage of adequately maintained transport facilities, traffic system inefficiency and settlement 
structure thereby causing congestion. Urban transport technology mix and misuse in these countries are reflected in the coexistence of motorized and non-motorized modes often resulting in congestion and accidents. Similarly, ineffective traffic management and enforcement are reflected in the ignorance and disrespect for traffic rules and regulations. Absence of road signs and uncontrolled growth of city hawkers, inefficient public transport service, e.g., an inadequate supply of public buses caused by an inadequate investment in it add to the misery of the transport users. Urban poor face transport problem as they being residents of cheaper peripheral areas of the city have to pay a high transport fare to go to work. Weak institutional support caused by a lack of coordination between national and subordinate levels of authorities and inadequacy of trained manpower further aggravate the problem (Gupta, 2007).

Construction of new roads, highways etc. and introduction of new modes of transport lead to an increased mobility and development of new areas, which may include residential, shopping or industrial areas. This in turn increases the land value in these areas. This is how transport creates positive externalities. However increased transport which is the result of urbanization creates problems of congestion and pollution. These are negative externalities created by transport. More than a million people are either killed in road accidents or die due to harmful effects of air pollution in the world. Vehicular emissions are the major source of air pollution particularly in developing countries like India (Chakrabartty \& Gupta, 2014).

Motorization in urban India is growing faster than the population; automobile ownership growth rates are of the order of $15 \%$ - 20\% per annum in most cities (Indiastat.com, 2008). As the urban population undertakes its daily mobility by a variety of transportation modes (local train, bus, car, etc.), the individual's modal choice is governed by a complex set of factors, viz., physical, human, economic and social. Even though public transport offers a competitive service, its market-share is constantly declining. In fact, there is a transition from public transit-orientated mobility towards private transport one (Pucher et al., 2005). Motorcycles in particular, as well as cars, are burgeoning as major forms of personal mobility, while walking and bicycling, once very prominent in cities, have taken a back seat. The increased use of private means of transportation is a major factor directly linked to energy use and environmental quality. In India, the share of public transportation peaks among people living in the megalopolis regions, where the supply networks and systems are appropriate (public transportation here includes trips done by bus and train) (World Bank, 2002). Post-1980, the use of motorcycle became an important factor in Indian metropolitan cities and, in particular, in medium-sized ones. The expanding use of two wheelers $(2 \mathrm{~W})$ in these cities is due to poor public transportation facilities. The younger population (20 - 35-age group), which accounts for nearly $60 \%$ of the population, use to rely mostly on 2-wheelers avoiding public transportation (IGIDR, 2008). Car driving is increasingly becoming dominating mode of transport in major cities. The dilemma policy makers are facing is: whether the policies should focus on accommodating growing levels of personal transport because driving more is apparently what the public wants or should the policies focus on limiting driving so as to reduce environmental and other costs? One obvious approach is to improve public transport facilities. Another is to improve quality of transit, bicycling, and walking, by enhancing accessibility (Reddy \& Balachandra, 2010).

Maparu and Pandit (2010) have estimated the delay in minutes on the different corridors of Kolkata to range from 20 minutes to about 60 minutes. This indicates that there is considerable congestion on the roads of Kolkata. Day by day the number of vehicles on the roads of Kolkata is increasing. Between 1996 and 2011, the vehicular population has doubled in Kolkata (Bhaduri, 2013).

The objective of this study is to estimate the cost of congestion in the city of Kolkata.

\section{Definition of Congestion}

Congestion is a situation in which demand for road space exceeds supply. Congestion is the impedance vehicles impose on each other, due to the speed-flow relationship, in conditions where the use of a transport system approaches capacity. Congestion is essentially a relative phenomenon that is linked to the difference between the roadway system performance that users expect and how the system actually performs. Urban traffic congestion must be understood in the wider context of city dynamics and agglomeration benefits. Traffic congestion in urban areas is often the outcome of successful urban economic development, employment; housing and cultural policies that make people want to live and work relatively close to each other and attract firms to benefit from the gains in productivity thus derived. There are many indications that, even though they may not be thrilled by the prospect, urban road users are prepared to live with crowded roads so long as they derive other benefits from 
living and working in their cities. Congestion prevents us from moving freely and it slows and otherwise disrupts the conduct of business within urban areas. However, it is important to note that unfettered movement is not the primary benefit we derive from living in urban areas. Cities provide access to a wide range of activities, people, services, goods, markets, opportunities, ideas and networks. These benefits can be delivered either through speed or through greater proximity. Congestion may affect travel speed but in some circumstances, such as dense urban cores, congestion may both be expected and, to some degree, accepted. In these cases, cities have come to accept a degree of congestion and continue to get along relatively well as long as overall accessibility is high (Managing Urban Traffic Congestion, European Conference of Ministers of Transport).

When measuring congestion, it is important to distinguish between the two main types of congestion, recurrent congestion and non-recurrent (incident) congestion. An understanding of recurrent congestion is necessary before non-recurrent congestion can be analyzed.

Recurrent congestion occurs mainly when there are too many vehicles wanting to use the road at the same time. Recurrent congestion typically occurs during weekday morning and afternoon peak periods, when most people go to work and return home at around the same time. In large urban areas, the peak periods can range from 6:00 to 9:30 a.m. and from 3:30 to 7:00 p.m. In smaller urban areas, the peaks may have a shorter duration (one or two hours). Of interest is the growing recurrent congestion that occurs during off-peak periods (i.e. during other weekday hours, and even on weekends). This reflects, in large part, a rapid growth in off-peak travel (off-peak travel is growing faster than peak-period travel in some areas). The result is that certain sections of expressways in Toronto and Montréal are regularly congested between the peak periods, essentially operating under all-day peak period conditions.

Non-recurrent congestion is the other main source of traffic congestion. Non-recurrent congestion is associated with random conditions or special and unique events, such as traffic incidents (disabled vehicles), truck spills, accidents, work zones, unusual or disruptive maneuvers by individual drivers, irregular facility of maintenance operations (e.g., seasonal street cleaners), adverse weather and special events. Because of the random nature of this type of congestion, non-recurrent congestion is more difficult to predict and address. The impact of non-recurrent congestion is significant, in that the reliability and predictability of travel time is of utmost importance to the public, to the goods-generating industries and to the economy in general. Variability in travel time leads to costly uncertainty for commuters and, in particular, for goods transporters who must meet fixed delivery schedules. Low variability in travel times can be even more important to the public than the actual duration of the trip. The ability to identify and measure different types of congestion, including the non-recurrent type, is the key to developing the appropriate mitigation solutions and policy responses (The Cost of Urban Congestion in Canada, 2006).

\subsection{Measurement of Congestion}

Though congestion is the fundamental concern in dealing with any transportation problem, the degree of congestion on urban arterial roadways is not always measured and treated uniformly, mainly because congestion is not a very well-defined phenomenon. It is measured either for area-wise conditions or for a specific location. The measured quantity may be a parameter of the quality of flow that travellers experience (e.g., travel time, delay, and queue length) or a parameter of the flow characteristics (e.g., density and occupancy). Congestion can be expressed also by the ratio between supply and demand or by the relative quality of traffic flow between ideal conditions and the prevailing conditions. The scale of measure may be a set of discrete classes [level of service $(\mathrm{LOS})=\mathrm{A}, \mathrm{B}, \mathrm{C} . .$. ] or a continuous value (e.g., a number between 0 and 1). Different approaches and measures that relate traffic congestion to the traveller's perceived quality of flow are recommended by Lomax et al. (1997), and Levinson and Lomax (1996). Traditionally, the use of LOS has been the most popular measure of congestion, in which the ratios between supply and demand are compared and put in one of six classes (A through F).

Measuring congestion is a necessary step in order to deliver better outcomes. Good indicators can be based on a wide network of roadway sensors but simple indicators based on less elaborate monitoring can sometimes adequately guide policy. What is important is to select metrics that are relevant to both road managers (e.g. speed and flow, queue length and duration, etc.) and road users (e.g. predictability of travel times, system reliability, etc.) (Managing Urban Traffic Congestion, European Conference of Ministers of Transport). 


\subsection{Congestion and Economics}

The theory of welfare economics shows that one of the conditions for achieving maximum economic efficiency is that all prices throughout an economy be set equal to marginal social costs. The word "social" indicates that all costs need to be taken into account, including any externalities. This means that optimal prices should include all resource costs and external costs (congestion, air pollution, accidents, noise, etc.). Estimating the marginal external costs of urban road transport is essential for calculating the marginal social cost. The marginal social cost is the sum of marginal private resource costs paid by the road user and the marginal external costs with respect to congestion, air pollution, noise and road accidents. Economic literature suggests that the marginal external costs of transport use correspond to the costs caused by an additional transport user that are not borne by the user himself but by others. They may consist not only of costs in the monetary sense, but also of, for example, time losses, pollution, noise, accidents and so on (Sen et al., 2010).

Traffic congestion is a widely recognized transport cost. It is often a major factor in transport system performance evaluation (www.vtpi.org/tca/tca0505.pdf). There are many approaches to measuring congestion costs. One approach is to determine the price needed to reduce traffic volumes to optimal roadway capacity (FHWA, 2006, www.ops.fhwa.dot.gov). Another approach is to calculate the marginal impacts each vehicles entering the traffic stream imposes on other road users, taking into account the speed-flow relationship of each road segment (Downs, 1992).

\subsection{Congestion Cost Studies}

Mayeres et al. (1996); Bickel et al. (1997); O’Mahony and Kirwan (2001), have used the following exponential congestion function to estimate marginal congestion cost. The function expresses the minutes needed to drive 1 $\mathrm{km}$ in a certain period as a function of the million PCU per hour at that moment in the city.

$$
1 / s=A_{1}+A_{2} \times\left(\exp \left(A_{3} \times q\right)\right)
$$

where " $\mathrm{s}$ " is average speed in kilometer per hour, "q" is million passenger car units (PCU) per hour and $\mathrm{A}_{1}, \mathrm{~A}_{2}$ and $\mathrm{A}_{3}$ are speed-flow relationship parameters (Sen et al., 2010).

Khan and Islam (2013) in their study calculate travel time costs, using value of time approach and vehicle operating cost, due to traffic congestion directly. The study further makes allowances for time variability loss, dead-weight loss, the avoidable social costs of congestion, externality cost due to travel time delay (imposed on others) and environmental damages. Estimated annual travel time cost is obtained as about USD 1499 million.

A study by the Canadian transport department titled "The Cost of Urban Congestion in Canada", developed congestion indicators for nine urban areas of Canada. The urban areas included Québec City, Montréal, Ottawa-Gatineau, Toronto, Hamilton, Winnipeg, Calgary, Edmonton and Vancouver. The study estimates that the total annual cost of congestion (in 2002 dollars) ranges from $\$ 2.3$ billion to $\$ 3.7$ billion for the major urban areas in Canada. More than 90 percent of this cost represents the value of the time lost to auto travellers (drivers and their passengers) in congestion. The remainder represents the value of fuel consumed (around 7 - 8 percent) and GHGs emitted under congestion conditions (around 2 - 3 percent).

http://www.adec-inc.ca/pdf/02-rapport/cong-canada-ang.pdf

\subsection{Congestion in Indian Cities}

In India, high population growth, high rate of urbanization and a high growth in the number of vehicles have led to the problem of congestion. In the absence of sufficient public transport, private vehicle ownership has grown in leaps and bounds and this is the reason why most of the Indian cities are chock-a-block (packed) with traffic.

As incomes rise, car loans proliferate and the auto industry churns out low-cost cars. Indians are rushing headlong to get behind the wheel. Indians bought 1.5 million cars in 2007, more than double of that in 2003. The cumulative growth of the Passenger Vehicles segment during April 2007-March 2008 was 12.17 percent. In 2007-2008 alone, 9.6 million motorized vehicles were sold in India. By some estimates, India is expected to soar past China this year as the fastest growing car market. India's population and its traffic are concentrated within its cities. The contrast between urban and rural India is far more pronounced than in most Western nations. The migration of rural population to urban areas in search of better job prospects has made cities densely populated. About 27 per cent the population lives in urban areas. There are 4000 cities and towns in India. About 400 cities 
have a population over 100,000. Eight cities have population more than 3 million (Uddin, 2009).

India has more truly congested cities than any other nation, which is not surprising, since it is also the world's second-most populous country, after China. Vehicles in India are distributed somewhat unevenly. Delhi, Mumbai, Kolkata and Bengaluru have $5 \%$ of India's population but $14 \%$ of its registered vehicles. Traffic is growing four times faster than the population in six cities: Mumbai, Delhi, Ahmedabad, Bengaluru, Chennai and Hyderabad. Indeed, Delhi is now said to have as many cars as Mumbai, Kolkata and Chennai combined. Traffic is well known for moving at the pace of its slowest component. Most countries have automobiles, buses, trucks, trains, motorcycles, motor scooters and bicycles. But in India, in addition to this routine urban transportation, and contributing substantially to the congestion, are networks of auto-rickshaws and two-wheelers, as well as bullock carts and hand-pulled rickshaws (disappearing from some urban areas). There has been a staggering 100 fold increase in the population of motorized vehicles; however, the expansion in the road network has not been commensurate with this increase. While the motor vehicle population has grown from 0.3 million in 1951 to over 30 million in 2004, the road network has expanded from 0.4 million km to 3.32 million km, only an 8 fold increase in terms of length during the same period. However, upgrading of roads by way of widening of carriage-ways, improved surface quality, strengthening/reconstruction of old/weak bridges and culverts, etc. has been carried out (Uddin, 2009).

A number of studies on congestion have been carried out for different cities of India. The effect of different types of vehicle on congestion has been captured on the basis of marginal congestion by Maitra et al. (2004). Using congestion models, the marginal congestions have been estimated for different road widths, traffic compositions and on-street parking levels. The peak hour vehicular composition and volume level vary for different roads in an urban area. Therefore, for assessing the operating conditions for different roads based on a comparable quantitative measure, the marginal congestion caused per Passenger Car Unit (PCU) of mixed traffic stream has been estimated and denominated "Marginal Congestion Index (MCI)". The use of MCI for prioritization of management actions for different urban roads has been discussed.

Singh \& Sarkar, (2009) made an attempt to determine congestion pricing in central area of Delhi that is Connaught Place with a view to ensuring desired Level of Service. Two methods for the determination of optimal pricing were adopted. The first method was related to the Point of pricing where the external costs were met by the revenue generated by the pricing level while the second method was the Pricing level needed to maintain a level of service C. By using these methods, pricing for car and two-wheeler motorized vehicles had been determined.

Varmora and Gundaliya (2013) in their study in the city of Ahmadabad have shown that due to change in carriageway width and vehicle composition, the traffic stream speed and flow also encounter more congestion level along the length of link.

Roy et al. (2011) discuss a novel and interesting way to detect the congestion on the urban arterials in India. They suggest using a Wi-Fi signal emitting device and a receiver across the road to identify the congestion. This method was found to be successful in terms of high accuracy of classifying the road as congested or free flowing (Rao \& Rao, 2012).

Sen et al. (2009) discussed the characteristics of the ITS techniques that need to be developed to cater the traffic conditions and congestion in developing regions and presented a brief description of a few efforts being made in this direction (Rao \& Rao, 2012).

\subsection{Congestion in Kolkata}

Kolkata has a high and dense population. One of the reasons for this is migration from the neighbouring states. Kolkata being a metropolitan city, people have migrated to Kolkata from other states. Another reason is the cross border migration from Bangladesh. Since the partition of India and through the Bangladesh War, the migration has continued and still continues because of the porous border between Indian and Bangladesh. But there was not enough work for such a large number of people and hence to survive these people took to hawking. Hawkers occupy a large section of road space in Kolkata. Not only the footpaths they encroach upon the roadways also. Encroachment of roads results in congestion (Chakrabartty \& Gupta, 2014).

As compared to Delhi and Mumbai, Kolkata has a much smaller road space of around 6\%. This space is further reduced due to encroachments. Moreover there is little scope of increasing the road space, at least in the core area, because it has built up in an unplanned way. Removal of encroachments involves social, political and economic costs. Building flyovers can ease congestion to some extent but there are hindrances to building them 
as well. In some areas, for building flyovers, land is required. Those living in these areas have to be relocated and this is resisted very strongly (Chakrabartty \& Gupta, 2014).

There has been an increase in incomes particularly for the urban middle class family resulting in an increased demand for vehicle ownership in this segment given the inadequacy of public transport. Also the number of working women has increased leading to both an increase in demand and supply of cars. The women have added to the demand for personal vehicles. Given, insufficient and unkempt public transport, inconvenience and lack of safety on public modes, the women who can afford generally opt for personal cars. Moreover, availability and affordability of low cost cars have made it easier for urban women to avail of it. The government's policy of liberalization has made the terms of car import easier and also increased car manufacture in India. This increased availability of cars coupled with easy car loan policy of banks has increased car ownership. The lack of initiative in improving the public transport system which is inadequate as well as unattractive has increased the number of private vehicles on Kolkata roads (Chakrabartty \& Gupta, 2014).

Mobility crisis begins to build up in a city when a large share of daily trips is made by personal vehicles that occupy more road space but carry fewer people, pollute more, and edge out walking, cycling, buses and intermediate public transport. Growing dependence of personal vehicles is already showing one of its worst impacts—gridlocked road (Chakrabartty \& Gupta, 2014).

The growth rate of cars has already overtaken that of two-wheelers in the city. Between 1998 and 2008 the car ownership by households has increased from a mere 1.73 percent to 11 percent in 2008, the ownership of two wheelers has increased from 5.67 percent to 16.5 percent. At the same time households that did not have any vehicle has fallen from 61 percent to 49.2 percent. Kolkata has 0.4 million cars as opposed to 1.3 million cars in Delhi which is severely gridlocked. What will happen if Kolkata has the same number of cars? Both cars and two wheelers occupy the maximum road space but carry just about 12 per cent of the daily trips in Kolkata. Share of cars in the traffic volume on key roads can be as much as 40 per cent but they meet only 4 per cent of the travel needs. This clearly shows that car users are a very small minority in the city. But a lot of things can go wrong if the city continues to design itself for car owners ignoring the travel needs of the majority which is using public transport and walking (Citizens report, air quality monitoring in Kolkata).

A study was done by Switch ON, Environment Conservation Society, in Kolkata in 2013 and Table 1 below gives a summary of their findings. They estimated the modal share of vehicles, road space share of vehicles and modal share of passengers on the city roads.

It is clear from the above table that cars cater to only $6 \%$ of the passengers but occupies $29 \%$ of the road space while buses serve $76 \%$ of the population and occupy only $32 \%$ of the road space. So public transport should be promoted in Kolkata so that the problem of congestion is addressed.

\section{Data and Methodology}

Data for the study have been obtained from the Kolkata Metropolitan Development Authority's (KMDA) report on mobility in Kolkata, titled Comprehensive Mobility Plan, 2008. The data includes Passenger Car Units (PCUs) on a few arterial roads of Kolkata during the morning peak and evening peak, the length of the roads in kilometers and corridor speeds. The morning peak has been taken to be from 9 to 10 a.m. and the evening peak, from 6 to 7 p.m. in the KMDA survey. The roads considered in the study include, Vivekananda Road, Chittaranjan Avenue (C. R. Avenue), Mahatma Gandhi Road (M. G. Road), R. G. Kar Road, A. J. C. Bose Road, Jawaharlal Nehru Road (J. L. N. Road), Lenin Sarani, Deshapran Sashmal Road, Raja S. C. Mallick Road and

\begin{tabular}{|c|c|c|c|c|c|c|c|c|c|}
\hline & $\begin{array}{l}\text { Private } \\
\text { Cars }\end{array}$ & Taxis & $\begin{array}{c}\text { Auto } \\
\text { Ricksha ws }\end{array}$ & $\begin{array}{c}\text { Buses, Mini } \\
\text { Buses }\end{array}$ & $\begin{array}{l}\text { Bikes, } \\
\text { Scooters }\end{array}$ & Bicycles & $\begin{array}{c}\text { Cycle Van, } \\
\text { Rickshaws, Carts }\end{array}$ & Tram & $\begin{array}{l}\text { Trucks, Vans, } \\
\text { Goods Carriage }\end{array}$ \\
\hline $\begin{array}{l}\text { Vehicle modal } \\
\text { Share }\end{array}$ & $31 \%$ & $20 \%$ & $13 \%$ & $12 \%$ & $15 \%$ & $3 \%$ & $2 \%$ & $0 \%$ & $4 \%$ \\
\hline $\begin{array}{c}\text { Vehicle } \\
\text { Road share }\end{array}$ & $29 \%$ & $18 \%$ & $7 \%$ & $32 \%$ & $4 \%$ & $1 \%$ & $1 \%$ & $0 \%$ & $8 \%$ \\
\hline $\begin{array}{l}\text { Passenger } \\
\text { Modal Share }\end{array}$ & $6 \%$ & $5 \%$ & $7 \%$ & $76 \%$ & $3 \%$ & $1 \%$ & $1 \%$ & $1 \%$ & $1 \%$ \\
\hline
\end{tabular}

Source: Report by Switch ON. http://switchon.org.in/India/congestionsurvey.pdf 
Jatindra Mohan Avenue. The value of time has been taken as Rs. 19 per passenger per hour. (Draft Final Report, KMDA, 2007).

Smeed (1968) in his paper "Traffic Studies and Urban Congestion", has given an equation for the calculation of time lost due to congestion. In the paper the relationship between the average speed of traffic $(v)$ and its amount $(q)$ is expressed as

$$
q=a-b v^{2} \text { or } q=q_{o}\left(1-v^{2} / v_{o}^{2}\right),
$$

where $v_{o}$ is the speed under light traffic conditions and $q_{o}$ is the maximum flow.

The time taken for a journey of length $l$ is $l / v$ at speed $v$ and $l / v_{0}$ at speed $v_{o}$. $C$ is defined as the time loss due to congestion which is given by the difference between the time taken by vehicles when the speed is $v$ and the time they would take if they were to move at the free flow speed or speed under light traffic conditions,

$$
C=q\left(l / v-l / v_{o}\right)
$$

The above formula derived by Smeed (1968) has been used to calculate the time loss on the roads of Kolkata. A pilot survey was done by the authors to find out the speed of cars and buses under free-flow conditions. The free flow speed of buses was found to lie between 30 to $40 \mathrm{~km} / \mathrm{hr}$ while that of cars was found to be between 60 to $70 \mathrm{~km} / \mathrm{hr}$ on Kolkata roads. The free flow speed for all vehicles in Kolkata has been taken as $50 \mathrm{~km} / \mathrm{hr}$. which is a rough average of that of buses and cars.

\section{Results and Discussion}

Table 2 below gives the time loss and the value of that time loss on a few arterial roads of Kolkata calculated using Smeed's formula, mentioned earlier.

As can be seen from the table, Rs. 74,077.66 is lost in only two hours (i.e. 9 - 10 a.m. and 6 - 7 p.m.) in a day only on the few selected roads. So the loss for peak hour congestion in a month would be Rs. 22, 22,329.8. The annual loss in monetary terms would be to the tune of Rs. 2, 66, 67,957.6. The actual loss is much more than this because the morning peak is seen to spread from 9 a.m. to 12 noon while the evening peak stretches from 5 p.m. to 8 p.m.

Increase in the number of vehicles is definitely one of the major causes of this rising congestion problem but there are certain other problems which are unique to Kolkata and are not present to such an overwhelming extent in the other metropolitan cities of India. One, there is heavy encroachment on Kolkata roads. A large number of road-side shops flow into the carriageway in Kolkata. Two, since the footpaths are occupied by hawkers, people

\begin{tabular}{ccccccc} 
Table 2. Congestion costs on Kolkata roads. & \multicolumn{1}{c}{} \\
\hline Arterial Roads & $\begin{array}{c}\text { Corrid-or } \\
\text { Speed }\end{array}$ & $\begin{array}{c}\text { Length of } \\
\text { Road }\end{array}$ & $\begin{array}{c}\text { PCUs at Morning } \\
\text { Peak }\end{array}$ & $\begin{array}{c}\text { PCUs in Evening } \\
\text { Peak }\end{array}$ & $\begin{array}{c}\text { Total Time Loss } \\
\text { (Hours) }\end{array}$ & $\begin{array}{c}\text { Value of Time } \\
\text { Lost (Rs.) }\end{array}$ \\
\hline Vivekananda Road & 40 & 1.2 & 1202 & 1768 & 17.82 & 338.58 \\
Chittaranjan Avenue & 25 & 4 & 2028 & 2112 & 331.2 & 6292.8 \\
Mahatma Gandhi Road & 9 & 3 & 1507 & 1599 & 848.97 & 16130.49 \\
$\quad$ R. G. Kar Road & 18 & 2 & 1397 & 1415 & 199.96 & 3799.32 \\
Acharya Jagadish Chandra & 18 & 6 & 1915 & 1851 & 803.41 & 15264.85 \\
Bose Road & 25 & 3 & 2237 & 2246 & 268.98 & 5110.62 \\
Jawaharlal Nehru Road & 20 & 2 & 1042 & 1225 & 136.02 & 2584.38 \\
Lenin Sarani & 15 & 2 & 1693 & 1848 & 330.49 & 6279.37 \\
Deshapran Sashmal Road & 16 & 4 & 2678 & 2487 & 878.05 & 16682.95 \\
Raja Subodh Mallick Road & 20 & 1 & 1390 & 1407 & 83.91 & 1594.29 \\
Jatindra Mohan Avenue & & & 17089 & 17958 & 3898.82 & 74077.66 \\
Total & & & & & \\
\hline
\end{tabular}

Source: Authors calculation. 
are forced to walk on the roads slowing down traffic. Three, hand-pulled carts coexist with motorized modes leading to congestion. Four, there is complete disregard for traffic rules on the part of the pedestrians as well as the drivers. Five, the habit of drivers to overtake other vehicles unnecessarily lead to traffic snarls and hence congestion. Last, on-road parking of vehicles reduces the road space further, leading to congestion.

\section{Strategies to Mitigate Congestion}

While the transport situation in India's rapidly growing cities is challenging, it is not hopeless. Indeed, local, state, and national governments could almost immediately undertake decisive actions that would greatly improve the situation, or at the very least, prevent its worsening (Pucher et al., 2005).

Improved Public Transport System: One of the ways to reduce congestion is to improve the public transport system. An efficient, fast, attractive, clean public transport system can reduce the number of private vehicles on the road. There is considerable evidence to suggest vehicle owners will use a mass transit system, if a good one is available. In fact, because of traffic snarls and the problem of finding parking space, many commuters in cities like New York and London choose to travel by the metro rail network (Uddin, 2009). In some routes in Kolkata, particularly those leading to the IT sector in Salt Lake, buses are air-conditioned, attractive and well maintained. These are used even by the private car owners (Chakrabartty \& Gupta, 2014).

Improved Traffic Management: This includes installing improved and technologically advanced traffic signalling devices. Stricter enforcement of traffic regulations on the road can also curtail congestion. This should also include proper training to drivers, so that they maintain lane discipline and not overtake continuously. Overtaking aggravates the problem of congestion. In Kolkata, as compared to say Mumbai drivers do not have any road discipline which causes more congestion (Chakrabartty \& Gupta, 2014).

Improved Rights of Way for Pedestrians: When the pedestrians overflow into the roadways from the footpaths then congestion is aggravated and the risk of accidents also increases. Thus there is a need to keep the footpaths clear of encroachments so that people can walk on them and not on the roads. There is also the need to build subways and footbridges where necessary and convenient. There are a number of footbridges in Kolkata but people hardly use those (Chakrabartty \& Gupta, 2014).

PPP in Maintaining and Running Buses: More private participation and investment in public transport, mainly buses, is needed. This can lead to more efficient and attractive public transport compared to the government owned ones. Public Private Partnership (PPP) is also required in building and maintaining roads (Chakrabartty \& Gupta, 2014).

Congestion Charging: Cities around the world such as Singapore and London have introduced congestion charging schemes to reduce traffic. For instance, in London, drivers are charged a fee for entering the Central London zone. The idea was to ensure that those using the road infrastructure made a financial contribution towards it, discourage vehicle owners from making unnecessary journeys and encourage the use of public transport systems. The results were impressive indeed: traffic in central London went down by about 21 per cent, and traffic speeds went up by about $10 \%$. Congestion charging brings with it a dual advantage: it reduces traffic on the roads and generates funds that can go towards improving alternative systems of transport (Uddin, 2009).

The government of India is planning to introduce congestion charging in the city of Delhi followed by those of Pune and Bangalore.

(http://articles.economictimes.indiatimes.com/2011-04-08/news/29396678_1_congestion-fee-private-vehicles-p ublic-transport). In Kolkata congestion charges can be introduced on a few roads leading to the Central Business District (Dalhousie Area), in the morning peak i.e. from 9 a.m. to 11 a.m. Collection of the toll or tax by an automated machine would be difficult, however, because of the investment involved in installing these machines and further in their maintenance, and also for administering difficulties, unless private sector can be drawn in (Chakrabartty \& Gupta, 2014).

It is true that congestion charge will dissuade people from making unnecessary trips during peak hours, but it may lead to distortion in income distribution. Many lower income people need to travel by public transport during peak hours. If they are made to pay the congestion charges in form of raised bus/tram fares, they have to be compensated somehow, may be in form of transport allowances; the government may not take that additional burden. On the other hand, transport price without congestion charge is itself a subsidy. In that case, public transport may be barred from entering the CBDs (Central Business District) in peak hours and riders made to walk. So, instead of raising bus fares in peak hours, car owners and other private vehicle owners may only be imposed the congestion charge (Chakrabartty \& Gupta, 2014). 


\section{Conclusions}

In the coming years traffic is expected to grow substantially in response to the mobility needs of the expanding population. Given the limited road space in the core city areas, this vehicular growth will lead to acute congestion in most of the Indian cities. To deal with these problems steps have to be taken, like inducting skilled staff, imparting administrative and technical training to the staff, utilizing more private resources, etc.

In the view of the fact that the road space in Kolkata is less compared to the other metro cites, the roads are narrow and the intersections are close-spaced, it is very difficult to address the problem of congestion. A concerted effort on the part of the local, state as well as the central government is required to tackle the problem. Imparting training to the drivers, improving signaling systems, etc. can be undertaken to improve traffic management. However, public mass transport usage should be encouraged and policies should be framed towards this end. Introduction of congestion charging in some areas should be contemplated very seriously to not just earn revenue but to dissuade people from using private vehicles.

\section{References}

Bhaduri, S. (2013). Vehicular Growth and Air Quality at Major Traffic Intersection Points in Kolkata City: An Efficient Intervention Strategy. The SIJ Transactions on Advances in Space Research \& Earth Exploration (ASREE), 1, 19-25.

Bickel, P., Schmid, S., Krewitt, W., \& Friedrich, R., Eds. (1997). External Costs of Transport in Extern E, Final Report. IER, Stuttgart.

Case on Cycle NMT Ban and Kolkata Congestion Survey, Report, Switch ON., 2013 http://switchon.org.in/India/congestionsurvey.pdf

Chakrabartty, A., \& Gupta. S., (2014). Traffic Congestion in the Metropolitan City of Kolkata. Journal of Infrastructure Development, 6, 43-59. http://dx.doi.org/10.1177/0974930614543046

Downs, A. (1992). Stuck in Traffic. Brookings Institute. www.brookings.edu.

European Conference of Ministers of Transport, Managing Urban Traffic Congestion, Summary Document available at: http://www.internationaltransportforum.org/jtrc/infrastructure/congestion/CongestionSummary.pdf

FHWA (2006). Congestion Pricing: A Primer, Federal Highway Administration. www.ops.fhwa.dot.gov www.ops.fhwa.dot.gov/publications/congestionpricing/congestionpricing.pdf

FHWA (2006). Travel Time Reliability: Making It There On Time, All The Time, Federal Highway Administration. http://ops.fhwa.dot.gov http://ops.fhwa.dot.gov/publications/tt_reliability/index.htm

Gupta, S. (2007). Passenger Transport Subsidy in West Bengal: Use or Misuse. New Delhi: Manak Publications.

http://onlinepubs.trb.org/onlinepubs/nchrp/nchrp rpt 398.pdf (accessed on 17. 5. 2014)

http://www.adec-inc.ca/pdf/02-rapport/cong-canada-ang.pdf (accessed on 19. 12. 2014)

http://www.cseindia.org/content/kolkata-city-dialogue-air-quality-and-transportation-challenge-agenda-action-0 (accessed on 4.8.2014)

http://www.igidr.ac.in/pdf/publication/WP-2010-023.pdf (accessed on 24. 9. 2014)

http://www.indiastat.com/transport/30/vehicles/289/registeredvehicles/16443/stats.aspx (accessed on 17. 9. 2014)

Indiastat.com (2008) (accessed on 15 November 2014).

Khan, T., \& Rashedul, I. Md. (2013). Estimating Costs of Traffic Congestion in Dhaka City. International Journal of Engineering Sciences and Innovative Technology, 2, 281-289

Levinson, H. S., \& Lomax, T. (1996). Development of Travel Time Congestion Index, Transportation Research Record. Journal of the Transportation Research Board, 1564, 1-10. http://dx.doi.org/10.3141/1564-01

Lomax, S. T. T., Turner, S., Shunk, G., Levinson, H. S., Pra, R. H., Bay, P. N., \& Douglas, G. B. (1997). Quantifying Congestion. Vol. 1, NCHRP Final Report 398, Washington DC: Transportation Research Board, 108 p.

Maitra, B., Sikdar, P. K., \& Dhingra, S. L. (2004) Modeling of Congestion: A Tool for Urban Traffic Management in Developing Countries. European Transport, 27, 45-56.

Maparu, T. S., \& Pandit, D. (2010). A Methodology for Selection of Bus Rapid Transit Corridors: A Case Study of Kolkata, Institute of Town Planners. India Journal, 7, 21-36.

Mayeres, I., Ochelen, S., \& Proost, S. (1996). The Marginal External Costs of Urban Transport. Transportation Research Part D: Transport and Environment, 1, 111-130. http://dx.doi.org/10.1016/S1361-9209(96)00006-5 
O’Mahony, M., \& Kirwan, K. J. (2001). Speed-Flow Relationship and Feasibility of Road-Pricing Technology. In: B. De Borger, \& S. Proost (Eds.), Reforming Transport Pricing in the European Union: A Modelling Approach (pp. 191-207). Cheltenham: Edward Elgar.

Pucher, J., Korattyswaropam, N., Mittal, N., \& Ittyerah, N. (2005). Urban Transport Crisis in India. Transport Policy, 12, 185-198. http://dx.doi.org/10.1016/j.tranpol.2005.02.008

Rao, A. M., \& Rao, K. R. (2012). Measuring Urban Traffic Congestion-A Review. International Journal of Traffic and Transport Engineering, 2, 286-305. http://dx.doi.org/10.7708/ijtte.2012.2(4).01

Reddy, B. S., \& Balachandra, P. (2010). Dynamics of Urban Mobility: A Comparative Analysis of Megacities of India. Mumbai: Indira Gandhi Institute of Development Research, December 2010.

Roy, S., Sen, R., Kulkarni, S., Kulkarni, P., Raman, B., \& Singh, L. (2011). Wireless across Road: RF Based Road Traffic Congestion Detection. In Proceedings of the the 3rd International Conference on COMmunication Systems and NETworkS (COMSNETS), Bangalore, 4-8 January 2011, 1-6.

Sen, A. K., Tiwari, G., \& Upadhyay, V. (2010). Estimating Marginal External Costs of Transport in Delhi. Transport Policy, 17, 27-37. http://dx.doi.org/10.1016/j.tranpol.2009.09.003

Sen, R., Sevani, S., Sharma, P., Koradia, Z., \& Raman, B. (2009). Challenges in Communication Assisted Road Transportation Systems for Developing Regions. Proceedings of the 3rd ACM Workshop on Networked Systems for Developing Regions, Big Sky, 11 October 2009, 6 p.

Singh, A., \& Sarkar, P. K. (2009). Determination of Congestion Cost in Central Business District of New Delhi-A Case Study. Journal of Indian Roads Congress, July-September.

Smeed, R. J. (1968). Traffic Studies and Urban Congestion. Journal of Transport Economics and Policy, 2, 33-70.

The Cost of Urban Congestion in Canada (April 2006) Transport Canada, Environmental Affairs.

Uddin, A. (2009). Traffic Congestion in Indian Cities: Challenges of a Rising Power, Kyoto of the Cities, Naples, March 26-28.

Varmora, K. K. C., \& Gundaliya, P. J. (2013). Effect of Traffic Composition and Road Width on Urban Traffic Stream. Indian Journal of Research-PARIPEX, Vol. II, Issue IV.

World Bank (2002). India’s Transport Sector: The Challenges Ahead. Washington DC: The World Bank. 